\title{
The transplant urologist's toolbox: Back-table ureteroscopy
}

\section{Thomas B. McGregor, MD, FRCSC}

Department of Urology, Queen's University, Kingston, ON, Canada

Cite as: Can Urol Assoc J 2017;11 (8):254. http://dx.doi.org/10.5489/cuaj.4780

See related article on page 251 .

$\mathrm{T}$ he ongoing discrepancy between the supply and demand of kidneys for transplant has lead many programs to review their policies on which donors and kidneys they deem acceptable for use. This has led to paradigm shift with the acceptance of donors, both deceased and living, that would have previously been turned down. Use of marginal deceased donors (donor after cardiac death [DCD] and expanded criteria donor [ECD]) has been well-accepted and has led to a significant expansion of the donor pool. Use of donors that have anatomic abnormalities, on the other hand, is a concept that continues to grow in popularity and has been shown in the literature to have positive impact on the donor pool. ${ }^{1,2}$

One such anatomic abnormality that is commonly encountered is that of the donor calculus. Often this can be detected on preoperative imaging and then dealt with endoscopically at the back table. This has been shown to be both feasible and successful in recent literature, as demonstrated here by Machen et al; however, it is not that uncommon for deceased donors to have no, or suboptimal imaging of their kidneys prior to organ procurement. In this situation, if the donor has a history of nephrolithiasis and no imaging, it would also be reasonable to consider endoscopic interrogation of the donor kidney collecting system prior to transplantation.

Back-table ureteroscopy is typically performed once the kidney has been flushed and then cooled in an ice bath. Distal ureter spatulation and stabilization with a stay-suture allows easy and safe passage of a flexible ureteroscope, with use of the usual endoscopic accessories, such as wires, baskets, and lasers. Machen et al have shown that it is also feasible to perform ureteroscopy on a kidney while on pump. This would prove advantageous, especially if such a kidney is shipped to a centre on pump, as often happens during a kidney paired donation.

Lastly, back-table ureteroscopy represents one of many urological techniques that lend themselves to renal transplant surgery. This highlights the vital role the urologist plays as part of the transplant team and the importance of transplant rotations as part of the urology residency training to ensure a strong presence in the transplant landscape moving forward. ${ }^{3}$

Competing interests: The author reports no competing personal or financial interests.

\section{References}

1. Olsburgh J, Thomas K, Wong K, et al. Incidental renal stones in potential live kidney donors: Prevalence, assessment, and donation, including role of ex-vivo ureteroscopy. BJU Int 2013;111:784-92. https://doi.org/10.1111/i.1464-410X.2012.11572.x

2. McGregor TB, Rampersad C, Patel P. Expanding living kidney donor criteria with ex-vivo surgery for renal anomalies. Can Urol Assoc J 2016;10:301-5. https://doi.org/10.5489/cuaj.3841

3. McGregor T, Bjazevic J, Patel $P$, et al. Changing of the guard? A glance at the surgical representation in the Canadian renal transplantation community. Can Urol Assoc J 2016;10:E7-11. https://doi.org/10.5489/cuaj.3256

Correspondence: Dr. Thomas B. McGregor, Department of Urology, Queen's University, Kingston, 0N, Canada; tom8mc@hotmail.com 